\title{
Surfactant Templated Mesoporous Hybrid Thin Films
}

HONGYOU FAN, YUNFENG LU, ROGER A. ASSINK, GABRIEL P. LOPEZ, and C.JEFFREY BRINKER

University of New Mexico/NSF Center for Micro-Engineered Materials, Department of Chemical \& Nuclear Engineering, The University of New Mexico, Albuquerque, NM 87131.

Sandia National Laboratories, Albuquerque, NM 87106.

\section{ABSTRACT}

Organic/inorganic hybrid films exhibiting ordered mesophases were prepared by a simple dip-coating procedure. Beginning with a homogeneous solution of tetraethyl orthosilicate, organoalkoxysilane $\left(\mathrm{R} \mathrm{Si}(\mathrm{OR})_{3}, \mathrm{R}\right.$ is a non-hydrolyzable functional ligand) surfactant, we relied on solvent evaporation to induce micellization and continuous self-assembly into hybrid silica-surfactant thin film mesophases. Surface acoustic wave (SAW)-based nitrogen sorption measurements indicate that the films have high surface areas and unimodal pore diameters after removal of surfactants.

\section{INTRODUCTION}

Organic-inorganic hybrid mesoporous silica (with controlled pore structure and tailored pore chemistry) could find many applications in new types of catalysis and separation, environmental and industrial processes, electronics, and sensors. ${ }^{[1-4]}$ A route to functionalized amorphous silica materials that has been widely investigated in sol-gel chemistry involves the co-condensation of organosilanes with silicate to produce hybrid organic-inorganic networks $[5$, 6]. In these materials, an organic functional group, $R$, is covalently bound to siloxane that is hydrolyzed to form silica copolymer. Mann et al. [7] first used this concept in direct synthesis of ordered organic-inorganic mesoporous powders containing octyl- and phenyl- groups in 1996, later extending to mesoporous materials containing mercapto-, amino-, epoxyl- groups. $[8,9]$ At the same time, several other studies were reported about direct synthesis of hybrid functional mesoporous silica[2, 10-12]. A solvent extraction procedure was used to remove the surfactant, resulting in a functionalized mesoporous product with a hexagonal MCM-41-type architecture. In each case mentioned above, the hybrid mesoporous silica was in the form of powder, precluding its use in such promising applications as membranes and optically-based sensors that generally require transparent, defect-freed supported thin films.

We recently reported on a rapid and continuous approach to form thin silica films with ordered mesoporous structures[13]. Films with 2-dimensional hexagonal, 3-dimensional hexagonal, cubic, or lamellar structures were prepared from initially homogenous silica sols by evaporation-induced surfactant enrichment during sol-gel dip-coating. In this paper, we extended our work to the preparation of hybrid organic/inorganic thin films with tailored pore surface chemistries.

\section{EXPERIMENTAL}

Precursor solutions were prepared by addition of surfactants (cationic, CTAB; $\mathrm{CH}_{3}\left(\mathrm{CH}_{2}\right)_{15} \mathrm{~N}^{+}\left(\mathrm{CH}_{3}\right)_{3} \mathrm{Br}$ or non-ionic, Brij-56; $\left.\mathrm{CH}_{3}\left(\mathrm{CH}_{2}\right)_{15}-\left(\mathrm{OCH}_{2} \mathrm{CH}_{2}\right)_{10}-\mathrm{OH}\right)$, organosilanes ( $\mathrm{R} \mathrm{Si}(\mathrm{OR})_{3}$, see Table 1), or organic molecules (see Table 1) to an acidic silica sol prepared from TEOS $\left[\mathrm{Si}\left(\mathrm{OCH}_{2} \mathrm{CH}_{3}\right)_{4}\right]\left(\mathrm{A} 2^{* *}\right)$. The acid concentration employed in the A2** synthesis procedure was chosen to minimize the siloxane condensation rate, thereby promoting facile selfassembly during printing. In a typical preparation, TEOS $\left[\mathrm{Si}\left(\mathrm{OCH}_{2} \mathrm{CH}_{3}\right)\right]$, ethanol, water and

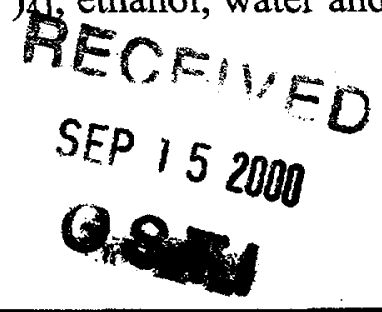




\section{DISCLAIMER}

This report was prepared as an account of work sponsored by an agency of the United States Government. Neither the United States Government nor any agency thereof, nor any of their employees, make any warranty, express or implied, or assumes any legal liability or responsibility for the accuracy, completeness, or usefulness of any information, apparatus, product, or process disclosed, or represents that its use would not infringe privately owned rights. Reference herein to any specific commercial product, process, or service by trade name, trademark, manufacturer, or otherwise does not necessarily constitute or imply its endorsement, recommendation, or favoring by the United States Government or any agency thereof. The views and opinions of authors expressed herein do not necessarily state or reflect those of the United States Government or any agency thereof. 


\section{DISCLAIMER}

Portions of this document may be illegible in electronic image products. Images are produced from the best available original document. 
dilute $\mathrm{HCl}$ (mole ratios: $1: 3.8: 1: 5 \times 10^{-5}$ ) were refluxed at $60 \mathrm{BC}$ for $90 \mathrm{~min}$. The sol was diluted with 2 volumes of ethanol followed by the further addition of water and $\mathrm{HCl}$. Organosilanes ( $\mathrm{R}-\mathrm{Si}(\mathrm{OR})_{3}$, (where $\mathrm{R}$ is a non-hydrolyzable organic functional ligand) were added followed by surfactants and (optionally) organic additives (see Table 1). Surfactants were added in requisite amounts to achieve initial surfactant concentrations $c_{0}$ ranging from 0.004 to $0.23 \mathrm{M}\left(c_{o}<<c m c\right)$. The final reactant molar ratios were: 1 TEOS : $22 \mathrm{C}_{2} \mathrm{H}_{5} \mathrm{OH}: 5 \mathrm{H}_{2} \mathrm{O}: 0.093-0.31$ surfactant : $0.039-0.8$ organosilanes : $2.10^{-5}$ organic additives. For the ethane-bridged silsesquioxane, $(\mathrm{RO})_{3} \mathrm{Si}-\left(\mathrm{CH}_{2}\right)_{2}-\mathrm{Si}(\mathrm{OR})_{3}(6)$, the neat precursor was diluted in ethanol and mixed with $1-8 \mathrm{wt} \%$ $\mathrm{CTAB}$ or Brij-56 surfactant followed by addition of an aqueous solution of $\mathrm{HCl}$. The final reactant molar ratios were: $\mathrm{Si}: \mathrm{EtOH}: \mathrm{H}_{2} \mathrm{O}: \mathrm{HCl}$ :surfactant $=1: 22: 5: 0.004: 0.054-0.18$. It should be noted that co-hydrolysis of organosilanes with TEOS in the initial A2** sol preparation, generally resulted in disordered worm-like mesostructures. After pattern deposition and drying, the surfactant templates were selectively removed by calcination in a nitrogen atmosphere at a temperature sufficient to decompose the surfactant molecules $(-350 \mathrm{BC})$ without degrading the covalently-bound organic ligands R. (confirmed by ${ }^{29} \mathrm{Si}$ MAS NMR spectroscopy $[14]$ ) or by solvent extraction.

Thin films were prepared by dip-coating the sols onto $<100>$ single crystal silicon wafers or ST-cut piezoelectric crystalline quartz surface acoustic wave (SAW) substrates at a rate of 50 $\mathrm{cm} / \mathrm{min}$. X-ray diffraction (XRD) (Siemens Model D500 diffractometer using Ni-filtered CuK_ radiation with $\lambda=1.5418 \AA$ in $\theta-2 \theta$ scan mode) combined with high-resolution transmission electron microscopy (HRTEM) (JEOL 2010, operating voltage $200 \mathrm{KV}$ ) were used to characterize the hybrid film mesostructures.

The films deposited on the SAW substrates were used to estimate surface area, pore size, and total pore volume. The SAW devices $(97 \mathrm{MHz})$ prepared with Ti-primed Au transducers were designed and fabricated at Sandia National Laboratories $[15,16]$. The measurements were conducted at $77 \mathrm{~K}$ by measuring the frequency shifts of the SAW device configured as the feedback element of an oscillation circuit during adsorption and desorption of nitrogen. The amount of nitrogen adsorbed as a function of relative pressure was determined from the frequency change, assuming that the SAW frequency is only perturbed by a mass loading variation. Nitrogen adsorption isotherms at $77 \mathrm{~K}$ were obtained by plotting the amount of nitrogen adsorbed versus the corresponding relative pressure of nitrogen. Surface areas were estimated by using the Brunauer-Emmet-Teller (BET) equation; pore radii (r) were estimated by modeling the pores as cylinders: the hydraulic radius $r=2 \mathrm{~V} / \mathrm{S}$, where $\mathrm{V}$ is the pore volume and $\mathrm{S}$ is the surface area.

\section{RESULTS AND DISCUSSION}

Figure 1A shows the X-ray diffraction pattern of a supported thin film prepared with $1 \mathrm{wt}$ $\%$ Brij-56. At low surfactant concentration (1 wt \%), silica-surfactant co-assembly results in the formation of a disordered mesophase composed of worm-like micelles. The $d$-spacing is about 42 (Figure 1A). Addition of tridecafluoro-1 ,1,2,2,-tetrahydrooctyltriethoxylsilane (1 in Table 1) results in favorable hydrophobic solvation of $R$ ' with the micellar interior, effectively increasing the surfactant tail volume $\boldsymbol{V}$. Increasing of surfactant tail volume drives the surfactant packing parameter $g\left(g=v / a_{0} l\right)$ toward 1.[17, 18] This procedure leads to the transformation of the worm-like micellar structure to a lamellar thin film mesophase. The corresponding XRD pattern (Figure 1B) after the addition of TFTS reflects first order and second order peaks. The transmission electron microscopy (TEM) image in Figure 2A shows a worm-like texture for the film prepared with $1 w t \%$ Brij-56. After addition of organosilane, TEM of the hybrid film shows a layered mesostructure with $d$-spacing $a=35.3$, consistent with the XRD results. 


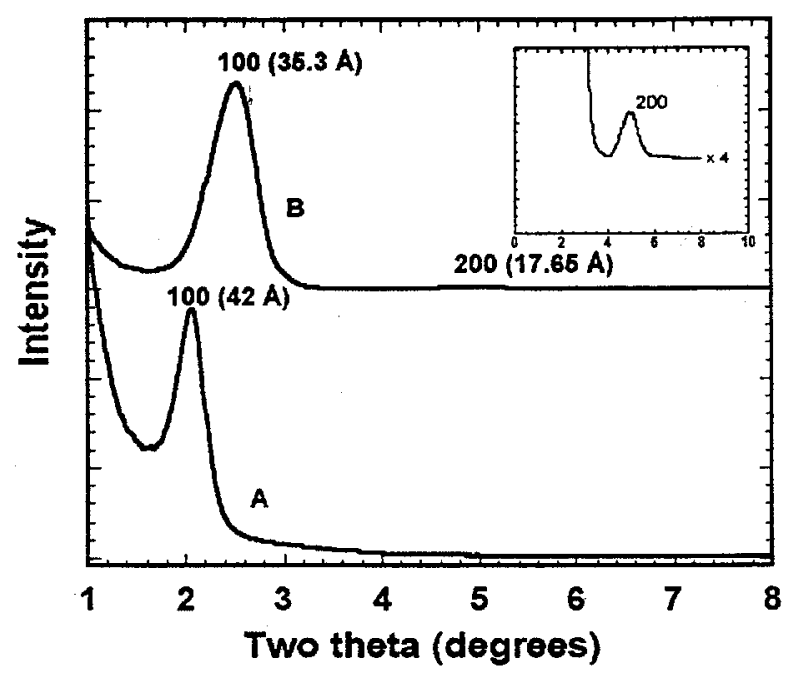

Figure $1 \mathrm{X}$-ray diffraction patterns of mesostructured silica thin films. (A) Film prepared by 1 wt\% Brij-56 and (B) film prepared by $1 \mathrm{wt} \%$ Brij-56 and TFTS.
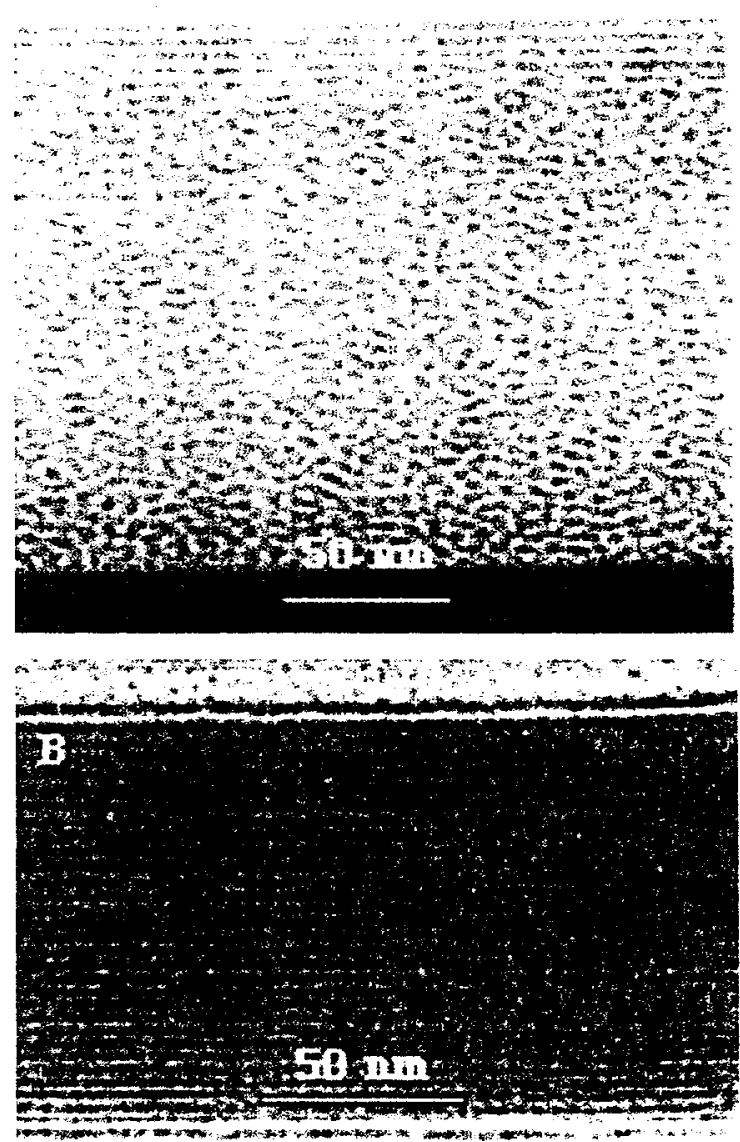

Figure 2 Cross-sectional TEM images of mesostructured silica films prepared by (A) $1 \mathrm{wt} \%$ Brij56 and (B) $1 w t \%$ Brij-56 and TFTS. 
The evidence from the above experiments has verified that the formation of hybrid organic/inorganic mesophase is based on a co-assembly process. During pre-reaction with water and oligomeric silica species within the A2** sol, organic silanes (TFTS) form functional silica oligomers. During dip-coating, preferential alcohol evaporation induces co-assembly of surfactants and co-polymerized organo oligomeric silicate into a liquid crystalline mesophase. Further drying and silica condensation solidify the mesostructure. Subsequent surfactant removal results in mesoporous films with organically modified pore surfaces. The whole mesoporous hybrid film is formed within a single step.

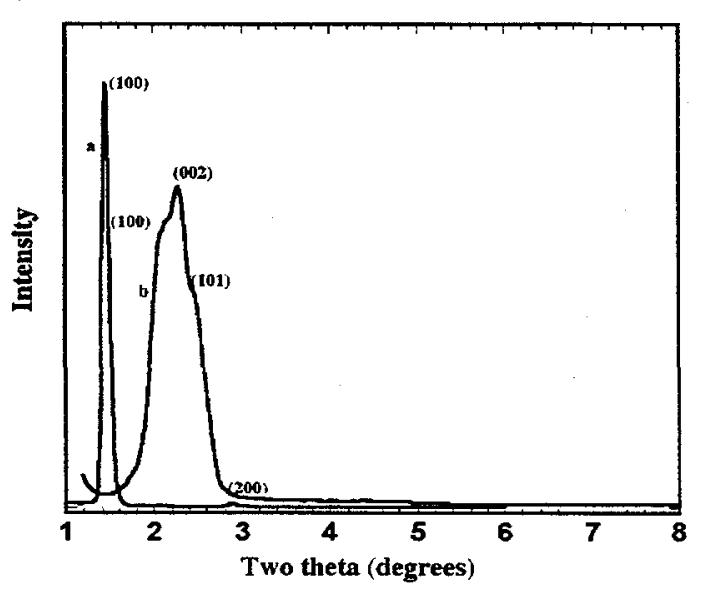

Figure 3. X-ray diffraction patterns of mesostructured hydrophobic silica films prepared by $4 \mathrm{wt} \%$ Brij-56 and TFTS. (a) Asdeposited film; (b) calcined in $\mathrm{N}_{2}$ at $390 \mathrm{BC}$ for three hours.

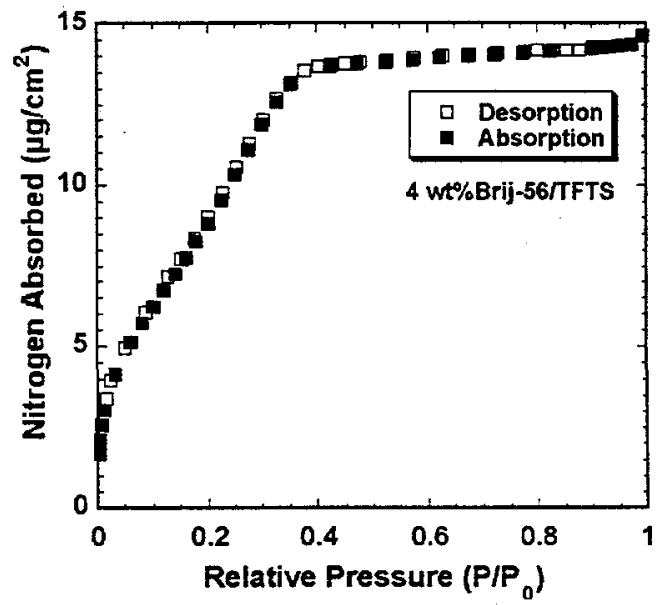

Figure 4. Nitrogen sorption isotherms (at $77 \mathrm{~K}$ ) of hydrophobic silica film measured by using a surface acoustic wave (SAW) technique.

Figure 3 shows XRD patterns of TFTS/silica mesostructured films prepared by $4 \mathrm{wt} \%$ Brij-56 and TFTS before and after calcination. For the as-deposited film, the XRD pattern has two peaks with $d$ spacings at $60 \AA$ and $30 \AA$. This pattern can be indexed as a one-dimensional hexagonal mesostructure. After calcination, the XRD is consistent with a three-dimensional hexagonal (3-dH) mesophase with unit cell constants $c=78 \AA$ and $a=46.2 \AA(c / a=1.68)$. The mesophase transition from 1-d hexagonal to 3-d hexagonal is consistent with the mesophase pathway of nonionic surfactant $[19]$.

Figure 4 shows the corresponding SAW-based $\mathrm{N}_{2}$ sorption isotherm of a calcined TFTS/silica mesoporous film prepared with $4 \mathrm{wt} \%$ Brij-56. The isotherm was acquired directly from a supported film without detachment from the substrate. It shows a type IV isotherm typical of surfactant templated mesoporous materials. The lack of hysteresis and absence of any appreciable adsorption at relative pressures above 0.3 is consistent with a uni-modal pore size distribution with no interparticle meso- or macroporosity, consistent with what is observed by TEM. The surface area calculated is $850 \mathrm{~m}^{2} / \mathrm{g}$, the pore diameter is 25 , and the fraction porosity is $50 \%$. The water contact angle is about $90_{i}$, and the measured dielectric constant $\mathrm{k}$ is 2.2 .

Utilizing hybrid sol-gel chemistry and co-assembly techniques, a variety of functional silica thin films have been prepared. The surfactants were removed in nitrogen at a low 
temperature or washing procedure while preserving the organo-silicon bonds[14]. The physical and chemical properties are summarized in Table 1.

Table 1. Chemical and physical properties of multiple functional mesoporous silica thin films.

\begin{tabular}{|c|c|c|c|c|c|}
\hline & $\begin{array}{l}\text { Functional Silanes }^{3} / \text { additives }^{4} \\
\text { R'-Si(OR) }\end{array}$ & Mesophase & $\begin{array}{c}\text { Pore Size } \\
(\AA)\end{array}$ & $\begin{array}{c}\begin{array}{c}\text { Surface Area } \\
\left(\mathrm{m}^{2} / \mathrm{g}\right)\end{array} \\
\end{array}$ & Properties and Applications \\
\hline 1 & $\begin{array}{c}\mathrm{F}_{3} \mathrm{C}\left(\mathrm{CF}_{2}\right)_{5} \mathrm{CH}_{2} \mathrm{CH}_{2} \mathrm{Si}\left(\mathrm{OC}_{2} \mathrm{H}_{5}\right)_{3} \\
\text { Tridecafluoro-1,1,2,2- } \\
\text { tetrahydrooctyltriethoxysilane (TFTS) }\end{array}$ & 3-dH & 25 & 850 & $\begin{array}{l}\text { Hydrophobic; } \\
\text { low k dielectrics }\end{array}$ \\
\hline 2 & $\begin{array}{c}\text { HS- }\left(\mathrm{CH}_{2}\right)_{3} \mathrm{Si}\left(\mathrm{OCH}_{3}\right)_{3} \\
\text { Mercaptopropyltrimethoxysilane (MPS) }\end{array}$ & 3-dH & 25 & 1060 & Coupling of noble metals \\
\hline $\mathbf{3}$ & $\begin{array}{c}\mathrm{NH}_{2}-\left(\mathrm{CH}_{2}\right)_{3} \mathrm{Si}\left(\mathrm{OCH}_{3}\right)_{3} \\
\text { Aminopropyltrimethoxysilane (APS) }\end{array}$ & cubic & 22 & 750 & $\begin{array}{l}\text { Coupling of noble metals, dye, } \\
\text { and bioactive molecules }\end{array}$ \\
\hline 4 & Dye'-NH- $\left(\mathrm{CH}_{2}\right)_{3} \mathrm{Si}\left(\mathrm{OCH}_{3}\right)_{3}$ & cubic & 21 & 545 & pH sensitive \\
\hline $\mathbf{5}$ & $\begin{array}{l}\mathrm{NH}\left(\mathrm{CH}_{2}\right)_{3} \mathrm{Si}\left(\mathrm{OC}_{2} \mathrm{H}_{5}\right)_{3} \\
\mathrm{NO}_{2}\end{array}$ & 3-dH & 22 & 560 & $\begin{array}{l}\text { Chromophore; nonlinear optical } \\
\text { material }\left(\chi^{2}\right)\end{array}$ \\
\hline 6 & $\left(\mathrm{H}_{5} \mathrm{C}_{2} \mathrm{O}\right)_{3} \mathrm{SiCH}_{2} \mathrm{CH}_{2} \mathrm{Si}\left(\mathrm{OC}_{2} \mathrm{H}_{5}\right)_{3}$ & cubic & 40 & 430 & low $\mathrm{k}$ dielectrics \\
\hline
\end{tabular}

${ }^{f}$ Additives investigated include rhodamine-B, cytochrome $c$ (from Fluka), oil blue $\mathrm{N}$, disperse yellow 3 (from Aldrich), silver ions and silver nanoparticles.

\# $\mathbf{4}$ was prepared by a conjugation reaction between a thin film mesophase containing $\underline{3}$ and the dye molecule (5,6-carboxyfluorecein, succinimidyl ester (5,6-FAM, SE) from Molecular Probes).

\section{CONCLUSIONS}

Mesoporous hybrid silica thin films with controlled pore surface chemistry can be readily prepared using a surfactant-templating approach through the dip-coating process. The formation of hybrid organic/inorganic mesophase is based on a co-assembly process. Nitrogen sorption results by SAW techniques show type IV isotherms with high surface areas. This approach offers a new pathway for the fabrication of functional porous thin films with both controlled pore structure and pore surface chemistry.

\section{ACKNOWLEDGEMENTS}

This work was funded by grants from US DOE Basic Energy Sciences Program, Sandia National Laboratory Laboratory-Directed Research and Development Program, and the University of New Mexico/NSF Center for Micro-engineered Materials. Sandia National Laboratory is a multiprogram laboratory operated by Sandia Corporation, a Lockheed Martin Company, for the United States Department of Energy under Contract DE-AC04-94AL85000.

\section{REFERENCES}

[1] X. Feng, G. E. Fryxell, L. Q. Wang, A. Y. Kim, J. Liu, K. M. Kemner, Science 276 (1997) 923-926.

[2] M. H. Lim, C. F. Blanford, A. Stein, Chemistry of Materials 10 (1998) 467-\&.

[3] S. Hall, C. Fowler, B. Lebeau, S. Mann, chem. commun. 2 (1999) 201-202.

[4] L. Mercier, T. J. Pinnavaia, Environmental Science \& Technology 32 (1998) 2749-2754.

[5] N. Husing, U. Schubert, Angew. Chem. v. 37(\#1-2) (1998) 23-45. 
N. Husing, U. Schubert, J. sol-gel Sci. \& Tech. v. 8(\#1-3) (1997) 807-812.

[7] S. L. Burkett, S. D. Sims, S. Mann, Chemical Communications (1996) 1367-1368.

[8] C. Fowler, S. Burkett, S. Mann, Chem Commun (1997) 1769-1770.

[9] C. E. Fowler, B. Lebeau, S. Mann, Chemical Communications (1998) 1825-1826.

[10] M. H. Lim, C. F. Blanford, A. Stein, Journal of the American Chemical Society 119 (1997) 4090-4091.

[11] M. Lim, A. Stein, Chem. Mater. 11 (1999) 3285-3295.

[12] K. Moller, T. Bein, R. X. Fischer, Chemistry of Materials 11 (1999) 665-673.

[13] Y. F. Lu, R. Ganguli, C. A. Drewien, M. T. Anderson, C. J. Brinker, W. L. Gong, Y. X. Guo, H. Soyez, B. Dunn, M. H. Huang, J. I. Zink, Nature 389 (1997) 364-368.

[14] H. Y. Fan, Y. F. Lu, A. Stump, S. T. Reed, T. Baer, R. Schunk, V. Perez-Luna, G. P. Lope, C. J. Brinker, Nature in press.

[15] G. C. Frye, S. J. Martin, A. J. Ricco, C. J. Brinker, ACS Symposium Series 403 (1989) 208-221.

[16] G. C. Frye, C. J. Brinker, A. Ricco, S. J. Martin, J. Hilliard, D. H. Doughty, Better Ceramics Through Chemistry IV (San Francisco, CA), Sol-gel coatings on acoustic wave devices: thin film characterization and chemical sensor development, pp. 583-593 (1990).

[17] J. Israelachvili, Intermolecular and surface forces, Academic Press, Inc., San Diego 1992.

[18] J. N. Isrealachvili, D. J. Mitchell, B. W. Ninham, J. Chem. Soc. 2 (1976) 1525-1568.

[19] H. Y. Fan, PhD Dissertation, The University of New Mexico, Albuquerque 2000. 